\title{
Accumulation of Circulating Macrophages in Lungs of Guinea Pigs Exposed to Hyperoxia
}

\author{
ROBERT L. BAEHNER, ${ }^{(23)}$ LAURENCE A. BOXER, COLEEN HIGGINS, AND GEORGE S. JOHNSON \\ Division of Pediatric Hematology/Oncology, James Whitcomb Riley Hospital for Children, Indiana University School \\ of Medicine, Indianapolis, Indiana, USA
}

\begin{abstract}
Summary
Superoxide dismutase (SOD) and glutathione peroxidase (GPx) key enzymes in alveolar macrophages regulating levels of superoxide anion and hydrogen peroxide, respectively, were observed to fluctuate in response to $\mathrm{FIO}_{2}$ of 50 and $85 \%$ for 18 to $90 \mathrm{hr}$. At the lower oxygen tension, SOD rose two-fold and GPX decreased significantly by $18 \mathrm{hr}$ and throughout the exposure periods compared to a delayed increase in SOD activity which was not sustained beyond $66 \mathrm{hr}$ of exposure and a sustained rise in GPx to an $\mathrm{FIO}_{2}$ of $85 \%$. Peritoneal macrophages containing lower SOD activity and greater GPx activity than resident alveolar macrophages upon injection into the circulation resulted in a $\mathbf{1 0 - f o l d}$ accumulation in the lungs during exposure of animals to $\mathrm{FIO}_{2}$ of $85 \%$ but not at $50 \%$. This study indicates that brief exposure to $\mathrm{FIO}_{2}$ of $85 \%$ but not $50 \%$ resulted in alterations of the vascular integrity of the lungs resulting in the accumulation of circulating macrophages to the alveolar macrophage pool. The delayed rise in SOD activity and the sustained increase in GPx activity in alveolar macrophages from animals exposed to $\mathrm{FIO}_{2}$ of $85 \%$ could in part be related to this influx of circulating macrophages with enzymatic characteristics observed for peritoneal macrophages.
\end{abstract}

\section{Speculation}

Toxic concentrations of oxygen not only affect the metabolism and enzyme responses of resident alveolar macrophages but incite the early influx of circulating macrophages into the lung favoring the accumulation of superoxide anion which could propagate the inflammatory reaction.

Pulmonary alveolar macrophages (AM) are equipped with a variety of enzymes to dispose of potentially damaging reduced oxygen by-products which are generated during hyperoxic conditions $(14,15)$. Two of these by-products, superoxide anion and hydrogen peroxide $\left(\mathrm{H}_{2} \mathrm{O}_{2}\right)$, have been shown to be toxic to the elaborating phagocytic cells themselves $(2,3)$ as well as to adjacent tissues $(6,13,21)$. Superoxide anion is converted to $\mathrm{H}_{2} \mathrm{O}_{2}$, in large part, by superoxide dismutase (SOD) located in both the cytosol and mitochondria $(8,12,22)$.

$\mathrm{H}_{2} \mathrm{O}_{2}$ in turn is metabolized to $\mathrm{H}_{2} \mathrm{O}$ by glutathione peroxidase (GPx) and catalase. Changes in the level of activities of these enzymes, especially SOD, in response to hyperoxia have been seen both in prokaryotic and eukaryotic cells $(9,17,18)$ including the AM (15). In the AM, the rate of rise of SOD is inversely linked to the concentration of inspired oxygen $\left(\mathrm{FIO}_{2}\right)(10,15)$. Furthermore, the release of $\mathrm{O}_{2}$ by AM phagocytizing opsonized zymosan is attenuated in AM exposed to hyperoxia (16). In this study, we have evaluated the cellular basis for the attenuated rise in SOD activity and the disparate response in GPX activity when animals were exposed to fractional inspired oxygen $\left(\mathrm{FIO}_{2}\right)$ of $50 \%$ compared to $85 \%$.

\section{MATERIALS AND METHODS}

Male guinea pigs ( 250 to $300 \mathrm{~g}$ ) were exposed to room air or to atmospheres of either 50 or $85 \%$ oxygen for 18 to $90 \mathrm{hr}$. The animals were maintained in plastic chambers at a temperature of $24^{\circ} \mathrm{C}$. An atmosphere of 50 or $85 \% \mathrm{FIO}_{2}$ was maintained by flowing humidified mixtures of oxygen and air through a Bennett $\mathrm{AO}-1$ air-oxygen mixer at a flow rate of 8 liters/min. The oxygen concentration was monitored with a Beckman oxygen monitor model M12 (Beckman Instruments). Guinea pig AM were isolated by lung lavage $(14,16)$. The alveolar macrophage cell suspensions were further purified on a Ficoll-Hypaque gradient (5) which achieved a purification of $95 \%$ viable macrophages as determined by exclusion of $0.2 \%$ trypan blue. Guinea pig peritoneal macrophages were obtained as previously described (14). Cell preparations were suspended in Krebs-Ringer phosphate $(\mathrm{pH} 7.4)$ at a cell concentration of $5 \times 10^{6} / \mathrm{ml}$ before sonication

Cell suspensions were then sonicated at $4^{\circ} \mathrm{C}$ for $1 \mathrm{~min}$ with a sonifier cell disruptor model W140 (Branson Power Corporation) at an output setting of 3 which disrupted greater than $99 \%$ of the cells. These sonicates were assayed for SOD (in the presence of 1 $\mathrm{mM}$ sodium azide to inhibit cytochrome $c$ reduction), catalase, and glutathione peroxidase activities as previously described (15). All sonicates were assayed for protein concentration by the method of Lowry et al. (11).

To investigate the possible influx of blood mononuclear cells into the lung after hyperoxic exposure for $18 \mathrm{hr}$, guinea pig peritoneal exudate macrophages were elicited after intraperitoneal injection of $1.2 \%$ sodium caseinate. Forty-eight to $72 \mathrm{hr}$ later, the monocytes were harvested from the peritoneal cavity and purified on a Ficoll-Hypaque gradient. Cells washed free of the Ficoll were resuspended in autologous plasma to provide a concentration of $1 \times 10^{7}$ monocytes per $\mathrm{ml}$ and were judged to be $95 \%$ free of contaminating cells and to be $95 \%$ viable as determined by Wright's stain smears and trypan blue exclusion, respectively. The macrophages were incubated with $200 \mu \mathrm{Ci}{ }^{51} \mathrm{Cr}$-labeled sodium chromate $\left({ }^{51} \mathrm{Cr}\right)$ at $37^{\circ} \mathrm{C}$ for $30 \mathrm{~min}$, washed free of unbound ${ }^{51} \mathrm{Cr}$, and resuspended in autologous plasma to yield a specific activity of approximately 25,000 to $30,000 \mathrm{dpm} / 10^{7}$ cells (4). Subsequently, $5 \times 10^{6}{ }^{51} \mathrm{Cr}$-labeled cells were injected by the intracardiac route and after $18 \mathrm{hr}$ of exposing guinea pigs to room air or to atmospheres of $\mathrm{FIO}_{2}$ of either 50 or $85 \%$, macrophages were harvested from the lungs by bronchial lavage. The cells were then counted for ${ }^{51} \mathrm{Cr}$ activity on a gamma counter.

\section{RESULTS}

\section{SOD AND GPX ACTIVITIES IN AM AFTER EXPOSURE OF GUINEA} PIGS TO $50 \%$ AND $85 \% \mathrm{FIO}_{2}$

As noted in Table 1, total SOD activities of AM obtained from guinea pigs exposed to $\mathrm{FIO}_{2}$ of $50 \%$ increased two-fold by $18 \mathrm{hr}$ after exposure and remained significantly elevated throughout the entire $90-\mathrm{hr}$ exposure period. In contrast, cells obtained from 
animals exposed to $\mathrm{FIO}_{2}$ of $85 \%$ demonstrated increased SOD activity of $1 \frac{1}{2}$-fold by $18 \mathrm{hr}$ and achieved a two-fold increase by $66 \mathrm{hr}$, which was not sustained beyond that time point. GPx activity decreased significantly by $18 \mathrm{hr}$ and remained depressed throughout the study period in the AM of animals exposed to $\mathrm{FIO}_{2}(50 \%)$. On the other hand, the GPx activity rose significantly by $42 \mathrm{hr}$ and remained elevated in cells obtained for animals exposed to $\mathrm{FIO}_{2}$ of $85 \%$. Catalase activity remained constant throughout the $90 \mathrm{hr}$ of exposure to an $\mathrm{FIO}_{2}$ of $50 \%$ and also remained constant for the initial $42 \mathrm{hr}$ of exposure to an $\mathrm{FIO}_{2}$ of $85 \%$ and then fell.

To determine whether the delayed increase in SOD activity and the increase in GPx activity may represent either a population of more youthful AM or an influx of mononuclear phagocytes from the circulation, peritoneal macrophages were radiolabeled with ${ }^{51} \mathrm{Cr}$ and injected into the circulation. These cells were selected because blood monocytes were not obtainable for purification in sufficient numbers for this study and because their myeloperoxidase activity is similar to blood monocytes (1). The immigration of circulating radiolabeled peritoneal macrophages into the lungs of guinea pigs exposed for $18 \mathrm{hr}$ to $\mathrm{FIO}_{2}$ of either 50 or $85 \%$ was monitored. As noted in Table 2, exposure of animals to $\mathrm{FIO}_{2}$ of $85 \%$ resulted in a 10 -fold increase in circulating ${ }^{51} \mathrm{Cr}$-labeled macrophages into the alveolar macrophage pool compared to the responses observed in animals exposed to room air or to an $\mathrm{FIO}_{2}$ of $50 \%$. Thus, the alterations in SOD activity observed at $\mathrm{FIO}_{2}$ of $50 \%$ is unlikely the result of an influx of circulating macrophages, whereas, the alterations of enzyme activities of AM from animals exposed to an $\mathrm{FIO}_{2}$ of $85 \%$ may, in part, reflect the influx of inflammatory macrophages containing lower total SOD, but higher GPx activity (Table 3).

\section{DISCUSSION}

The ready access to AM by bronchial lavage provides a means for assessing enzymatic and functional consequences of hyperoxia

Table 1. SOD, GPx, and catalase activities in AM obtained from guinea pigs during hyperoxia ${ }^{1}$

\begin{tabular}{cccccccc}
\hline $\begin{array}{c}\mathrm{FIO}_{2} \\
(\%)\end{array}$ & $\begin{array}{c}\mathrm{Hr} \text { of } \\
\text { exposure }\end{array}$ & $n$ & $\begin{array}{c}\text { SOD } \\
(\%)\end{array}$ & $n$ & $\mathrm{GPx}(\%)$ & $n$ & $\begin{array}{c}\text { Catalase } \\
(\%)\end{array}$ \\
\hline 50 & 0 & $11^{2}$ & 100 & 5 & 100 & 5 & 100 \\
& 18 & 9 & $205 \pm 6^{3,4}$ & 6 & $76.1 \pm 4.6^{4}$ & 6 & 98.4 \\
& 42 & 9 & $191 \pm 5^{4}$ & 6 & $65.1 \pm 4.6^{4}$ & 6 & 103.7 \\
& 66 & 8 & $189 \pm 3^{4}$ & 12 & $48.6 \pm 2.8^{4}$ & 12 & 97.5 \\
& 90 & 9 & $188 \pm 3^{4}$ & 12 & $58.7 \pm 2.8^{4}$ & 12 & 97.6 \\
85 & 0 & 12 & 100 & 5 & 100 & 5 & 100 \\
& 18 & 14 & $156 \pm 12^{4}$ & 7 & $114 \pm 9^{4}$ & 7 & 95.8 \\
& 42 & 15 & $169 \pm 6^{4}$ & 4 & $147 \pm 12^{4}$ & 4 & 92.7 \\
& 66 & 15 & $194 \pm 6^{4}$ & 9 & $185 \pm 16^{4}$ & 9 & 87.3 \\
& 90 & 16 & $106 \pm 12$ & 9 & $186 \pm 18^{4}$ & 9 & 54.8 \\
\hline
\end{tabular}

"Activities expressed as \% of zero time. See "Materials and Methods" for details. Control SOD GPx and catalase absolute values were $16.8 \pm$ 0.7 , and 11.6 , and $245 \pm 23$ units/mg protein, respectively.

${ }^{2}$ Numbers in parentheses, number of individual animals studied.

${ }^{3}$ Mean \pm S.E.

Table 2. Immigration of ${ }^{51} \mathrm{Cr}$-labeled sodium chromate macrophages into the lung of guinea pigs after $18 \mathrm{hr}$ of hyperoxic exposure

\begin{tabular}{lc}
\hline Exposure & cpm $/ 10^{6}$ cells \\
\hline Air & $41.9 \pm 12^{\prime}$ \\
$50 \% \mathrm{O}_{2}$ & $39.4 \pm 14$ \\
$85 \% \mathrm{O}_{2}$ & $414 \pm 10^{2}$ \\
\hline
\end{tabular}

${ }^{1}$ Mean \pm S.E. of three separate experiments with five animals for each group.

${ }^{2}$ Significantly different from other values; $P<0.05$.
Table 3. Comparison of SOD and GPX activities in $A M$ and peritoneal macrophages

\begin{tabular}{lcc}
\hline & $\begin{array}{c}\text { SOD (units/mg pro- } \\
\text { tein) }\end{array}$ & $\begin{array}{c}\text { GPx (units/mg/ } \\
\text { min) }\end{array}$ \\
\hline AM & $16.8 \pm 0.7^{1}$ & $11.6 \pm 0.7$ \\
Peritoneal macrophage & $12.60 \pm 0.16$ & $23.7 \pm 2.3$ \\
\hline
\end{tabular}

${ }^{1}$ Mean \pm S.E. of three separate experiments with five animals for each group.

in at least one type of lung cell. In the guinea pig model, SOD activity rises by two-fold during the first $18 \mathrm{hr}$ of exposure of animals to $\mathrm{FIO}_{2}$ of $50 \%$ and remains elevated throughout $90 \mathrm{hr}$ of exposure, whereas a lethal concentration of $85 \%$ resulted in a retarded rise of SOD activity which could not be sustained at 90 hr. Others have failed to observe increases in SOD activity of alveolar macrophages in adult murine models (7) but have observed changes in neonatal cells (19).

GPx, another enzyme which catalyzes the oxidation of reduced glutathione by hydrogen peroxide was also previously found to be responsive to the effect of hyperoxia (15). At lower oxygen concentrations, GPx activity fell but at the higher concentrations it rose. On the other hand, catalase remained relatively constant at the lower and higher concentrations until the late exposure periods when it fell (15). In an attempt to account for the variable effect of $\mathrm{FIO}_{2}$ of $85 \%$ in provoking as much rise in SOD activity coupled with a more rapid increase in GPx, we considered that the higher oxygen tension might induce early inflammatory changes in the lung leading to substantial immigration of circulating mononuclear phagocytes into lung (20). Peritoneal macrophages labeled with ${ }^{51} \mathrm{Cr}$ when infused intravenously accumulated in large amounts in the lung of animals exposed to $\mathrm{FIO}_{2}$ of $85 \%$ compared to animals exposed to $\mathrm{FIO}_{2}$ of $50 \%$ or room air. There was a 10 fold enrichment of labeled cells in the bronchial lavages obtained from animals at $18 \mathrm{hr}$ of exposure to $\mathrm{FIO}_{2}$ of $85 \%$ compared to $\mathrm{FIO}_{2}$ of $50 \%$ room air. These studies indicate that the higher oxygen tension incites an accelerated influx of mononuclear phagocytes from the circulation into the lungs (20). The delayed rise in SOD activity and the increase in GPx in the cells obtained by bronchial lavage at these early time points may reflect contamination of the pool of AM with circulating monocytes. Blood monocytes resemble the peritoneal monocyte in myeloperoxidase activity and energy metabolism (7) and probably contain similar levels of SOD and GPX.

\section{CONCLUSION}

The blunted rise in SOD activity and the prompt sustained rise in GPx activity in AM from guinea pigs exposed to $\mathrm{FIO}_{2}$ of $85 \%$ is in part due to an influx of inflammatory blood mononuclear cells containing lower SOD and higher GPx activity than AM. At less toxic $\mathrm{FIO}_{2}$ of $50 \%$, the SOD activity reaches higher levels by $18 \mathrm{hr}$, and the GPx activity falls in the AM, and these fluctuations are not associated with an influx of blood monocytes and reflects an intrinsic response of the AM to hyperoxic stress.

\section{REFERENCES AND NOTES}

1. Albrecht, R. M., and Houg, R.: Basic and clinical considerations of the monocytemacrophage system in man, J. Pediatr. 88: 751 (1976).

2. Baehner, R. L., Boxer, L. A., Allen, J. A., and Davis: Autooxidation as a basis for altered function by polymorphonuclear leukocytes. Blood, 50: 327 (1977).

3. Boxer, L. A., Richardson, S. B., and Baehner, R. L.: Effects of surface-active agents on neutrophil receptors. Infect. Immun., 21: 28 (1978).

4. Boxer, L. A., and Stossel, T. P.: Effects of anti-human neutrophil antibodies in vitro. J. Clin. Invest., 53: 1534 (1974).

5. Boyum, A.: Isolation of mononuclear cells and granulocytes from human blood, Scand. J. Clin. Lab. Invest., 21(Suppl.):97: 77 (1967)

6. Clark, J. M.: The toxicity of oxygen. Am. Rev. Respir. Dis., 110: (Part 2): 40 (1974).

7. Denake, S. M., Bernstein, S., and Fanburg, E. L.: Absence of inductive effect of hyperoxia on superoxide dismutase activity in rat alveolar macrophages, Am. Rev. Respir. Dis., 118: 105 (1978). 
8. Fridovich, I., Superoxide radical and superoxide dismutase. Accounts Chem. Res., 5: 321 (1972).

9. Gregory, E. M., Goscin, S. A., and Fridovich, I.: Superoxide dismutase and oxygen toxicity in a eukaryote, Bacteriology, 117: 456 (1974).

10. Johnson, G. S., Rister, M., Higgins, C., Manfredi, F., and Baehner, R. L.: Biochemical basis of oxygen toxicity in guinea pig alveolar macraphages and granulocytes. In: Pulmonary Macrophage and Epithelial Cells. Proceedings of the Sixteenth Annual Hanford Biology Symposium, Vol. 43, pp. 509-522 (Richland, Washington, D. C., 1976).

11. Lowry, O. H., Rosenbrough, N. J., Farr, A. L., and Randall, R. J.: Protein measurement with the Folin phenol reagent. J. Biol. Chem., 193: 265 (1951).

12. McCord, J. M., and Fridovich, I.: Superoxide dismutase, an enzyme function for erythrocuprein (hemocuprein). J. Biol. Chem., 24I: 6049 (1969).

13. Pratt, P. C.: Pathology of pulmonary oxygen toxicity. Am. Rev. Respir. Dis., 110 (Part 2): 51 (1974).

14. Rister, M., and Baehner, R. L.: A comparative study of superoxide dismutase activity in polymorphonuclear leukocytes, monocytes, and alveolar macrophages of the guinea pig. J. Cell. Physiol., 87: 345 (1976).

15. Rister, M., and Baehner, R. L.: The alteration of superoxide dismutase, catalase, glutathione peroxidase, and $\mathrm{NAD}(\mathrm{P}) \mathrm{H}$ cytochrome $c$ reductase in guinea pig polymorphonuclear leukocytes and alveolar macrophages during hyperoxia. $\mathbf{J}$. Clin. Invest., 58: 1174 (1976).

16. Rister, M. and Baehner, R. L.: Effect of hyperoxia on superoxide anion and hydrogen peroxide production of polymorphonuclear leukocytes and alveolar

Copyright $(1981$ International Pediatric Research Foundation, Inc

$0031-3998 / 81 / 1510-1356 \$ 02.00 / 0$ macrophages. Br. J. Haematol., 36: 241 (1977).

17. Simon, L. M. Liu, J., Theodore, J, and Robin, E. D. Effect of hyperoxia hypoxia and maturation on superoxide dismutase activity in isolated alveolar macrophages, Am. Rev. Respir. Dis., 115: 279 (1976).

18. Stevens, J. B., and Autor, A. P., Induction of superoxide dismutase by oxygen in neonatal rat lung. J: Biol. Chem., 252: 3509 (1977).

19. Stevens, J. B., and Autor, A. P.: Oxygen-induced synthesis of superoxide dismutase and catalase in pulmonary macrophages on neonatal rats. Lab. Invest. 37: 470 (1977).

20. Van Oud Ablas, A. B., and Van Furth, R.: Origin, kinetics and characteristics of pulmonary macrophages in the normal steady state. J. Exp. Med., 149: 1504 (1979).

21. Weibel, E. R.: Oxygen effect on lung cells. Arch. Intern. Med., 128: 54 (1971).

22. Weisiger, R. A., and Fridovich, I.: Superoxide dismutase (organelle specificity), J. Biol. Chem., 248: 3583 (1973).

23. Requests for reprints should be addressed to: Robert L. Baehner, M.D. Division of Pediatric Hematology/Oncology, James Whitcomb Riley Hospital for Children, Indiana University School of Medicine, Indianapolis, IN 46223 (USA).

24. This research was supported grant ROI HL 19779-04 from the Public Health Services National Institutes of Health and a grant from the Riley Memorial Association. This work was done during the tenure of Dr. Boxer as an Established Investigator of the American Heart Association.

25. Received for publication July 15, 1980.

26. Accepted for publication February 2, 1981. 